\title{
Effect of layered silicate reinforcement on the structure and mechanical properties of spent polyamide-12 nanocomposites
}

\author{
B. Aldousiri, H.N. Dhakal*, S. Onuh, Z.Y. Zhang, N. Bennett, M.O.W. Richardson \\ Advanced Polymer and Composites (APC) Research Group, Department of Mechanical E Design Engineering, University of Portsmouth, PO1 3DJ, UK
}

\section{A R T I C L E I N F O}

\section{Article history:}

Received 17 May 2011

Received in revised form 22 June 2011

Accepted 2 August 2011

Available online $\mathrm{xxxx}$

\section{Keywords:}

A. Polymer nanocomposites

B. Mechanical properties

D. Transmission electron microscope (TEM)

E. Injection moulding

\begin{abstract}
A B S T R A C T
The aim of this work was to study the structure and mechanical properties of spent polyamide- 12 and spent polyamide-12/layered silicate reinforced novel nanocomposites. Layered silicate at 1, 3, 5 and $7 \mathrm{wt} . \%$ was incorporated in spent polyamide- 12 and its nanocomposites were prepared using single screw injection moulding technique. The interlamellar structure and surface morphology were characterised by transmission electron microscope (TEM) and scanning electron microscope (SEM). Different levels of layered silicate dispersion (as characterised by TEM and SEM) correlated strongly with improvements in mechanical performance. The results showed that the tensile and flexural properties are found to be increased with the incorporation of layered silicate into spent PA-12 matrix. Comparison of tensile and flexural test results between virgin PA-12, spent PA-12 and spent PA-12 nanocomposites showed that spent PA- 12 samples have retained $70 \%$ of its tensile and $80 \%$ of its flexural properties respectively, compared to virgin PA-12.
\end{abstract}

(c) 2011 Elsevier Ltd. All rights reserved.

\section{Introduction}

In the last couple of decades, polymer-clay nanocomposites (PCN) have attracted considerable interest because of the improvements in mechanical, thermal and barrier properties of organic polymer matrix at a low clay loading [1-4]. Among the inorganic materials, layered silicates have been receiving special attention in the field of nanocomposites because of their ability to disperse into individual layers. The pioneering work undertaken by Toyota research group on the synthesis of Nylon-6 nanocomposites exhibited significantly improved mechanical and thermal properties with the reinforcement of as little as $4.7 \mathrm{wt}$.\% layered silicate [5-7].

There are many reported works in the field of polymer nanocomposites, for polyamide 6/montmorillonite nanocomposites [8-11] for polyamide-11 [12-15] and for polyamide-12 [16-19]. Most of the publications are focused in the properties of polyamide nanocomposites reporting improvements in physical, mechanical and thermal properties as a result of the reinforcement effect of high aspect ratio nano particles. However, there are hardly any reported works investigating the properties of spent PA-12 and the effect of reinforcing them with layered silicates.

Polyamide- 12 is one of the high performance polymers used in a wide variety of industrial applications due to its high mechanical properties, rigidity, good thermal and chemical stability [16]. Typical applications of polyamide- 12 in recent years have been fully functional prototypes as well as final products used in aero-

\footnotetext{
* Corresponding author. Tel.: +44 (0) 239284 2582; fax: +44 (0) 2392842351.

E-mail address: hom.dhakal@port.ac.uk (H.N. Dhakal).
}

space, automotive, electronics and packaging industries. When petrochemical products, including PA-12, have reached the end of their service life, the so called spent materials are replaced with new products that have to be manufactured from virgin raw materials, and the spent products are typically disposed of in a landfill, wasting valuable natural resources. The disposing of spent materials can become a serious environmental challenge.

Novel and efficient materials for automotive, aerospace and packaging applications based on spent PA-12 nanocomposites can provide solutions to the demand of increased mechanical performance as well as environmental benefits such as reduction of volume of waste to be disposed in landfills. Therefore, the utilisation of spent PA-12 mixed with virgin PA has great potential for making parts using modern manufacturing processes such as selective laser sintering (SLS). Furthermore, the mechanical properties of spent polyamide can be further enhanced with the addition of small amount of layered silicates up to $5 \mathrm{wt} . \%$.

The aim of this study was to characterise the interlamellar structure and morphology and to investigate the effect of various loading levels of layered silicates reinforcement on the mechanical properties of spent PA-12. Results from SEM and TEM are correlated with the results from tensile and flexural tests.

\section{Experimental}

\subsection{Materials}

In this study, spent polyamide (PA-12) was used as the matrix material (mix ratio of $55 \mathrm{wt} . \%$ spent and $45 \mathrm{wt} . \%$ virgin,) and was 
provided by the Centre for Rapid Design and Manufacturing (CRDM), Buckinghamshire, UK. The filler material used was layered silicate (LS), commercially known as LK-PA-CR1. Both polymer and filler materials were obtained as fine white powder.

\subsection{Preparation of spent $P A-12$ and its nanocomposites}

The spent polyamide (PA-12) and layered silicate were dried separately in a fan assisted oven at $100{ }^{\circ} \mathrm{C}$ for $1 \mathrm{~h}$ in order to remove the residual moisture as these both materials absorb water very easily. A dry grinding process was employed in mixing various weight percentages $(1,3,5$ and 7 wt.\%) of LS with spent PA-12. A high speed rotary Kenwood blender was used at a rotary speed of $800 \mathrm{rpm}$ for $10 \mathrm{~min}$. All samples were prepared using the same parameters to ensure consistency of the mixing. Test specimens for morphological and mechanical analyses were then prepared using a MCP Mini Moulder 12/90 HSP with a temperature profile of $240-260^{\circ} \mathrm{C}$ with screw speed of $200 \mathrm{rpm}$.

\subsection{Characterisation}

\subsubsection{Transmission electron microscopy (TEM)}

TEM measurements on spent PA-12/nanocomposite systems were performed using a high-resolution transmission electron microscope (Phillips CM12 with an associated Gatan digital camera system). Block faces were prepared from each system then ultrathin sections of about $55 \mathrm{~nm}$ were collected using a diamond knife in a Reichert Ultracut E ultramicrotome. Due to the nature of the material it was found beneficial to use faster cutting speeds, with $30 \mathrm{~mm} / \mathrm{s}$ generally being optimum.

\subsubsection{Scanning electron microscopy (SEM)}

The morphology of spent PA-12/nanocomposite systems was further investigated in an Hitachi S4500 SEM working at an operating voltage of $8 \mathrm{kV}$. The same block faces used for the TEM examination were also used for SEM, with plasma etching used to preferentially remove polyamide in order to leave the clay particles sitting proud of the surface. After adhering to SEM stubs, a thin layer of gold/palladium was applied to the specimens prior to SEM examination.

\subsection{Mechanical testing}

The tensile strength and modulus of spent PA-12 and spent PA12 /nanocomposites were measured using a Lloyd's 4505 instrument. The crosshead speed applied for the tensile tests was $10 \mathrm{~mm} / \mathrm{min}$. The specimen's shape adhered to the standards and specifications of the British Standard BS ISO 20753:2008. The flexural strength and modulus of spent PA-12 and its nanocomposites were determined using the same instrument but in a three-point bending mode using a cross head speed of $2 \mathrm{~mm} / \mathrm{min}$. The three point bending test specimens were $60 \mathrm{~mm}$ long, $15 \mathrm{~mm}$ width and $3 \mathrm{~mm}$ thick. The dimensions and the geometry of the specimens were in accordance with the British Standard and specification BS EN 2746:1998.

\section{Results and discussion}

\subsection{The interlamellar structure and surface morphology}

Fig. 1 represents the TEM micrographs of different samples at higher magnification $(50 \mathrm{~nm})$, in which the bright region represents the matrix phase and the dark lines correspond to the stacked and intercalated silicate layers. Nanocomposites with 5 wt.\% nanoclay show a well separated stacked arrangement of sil-
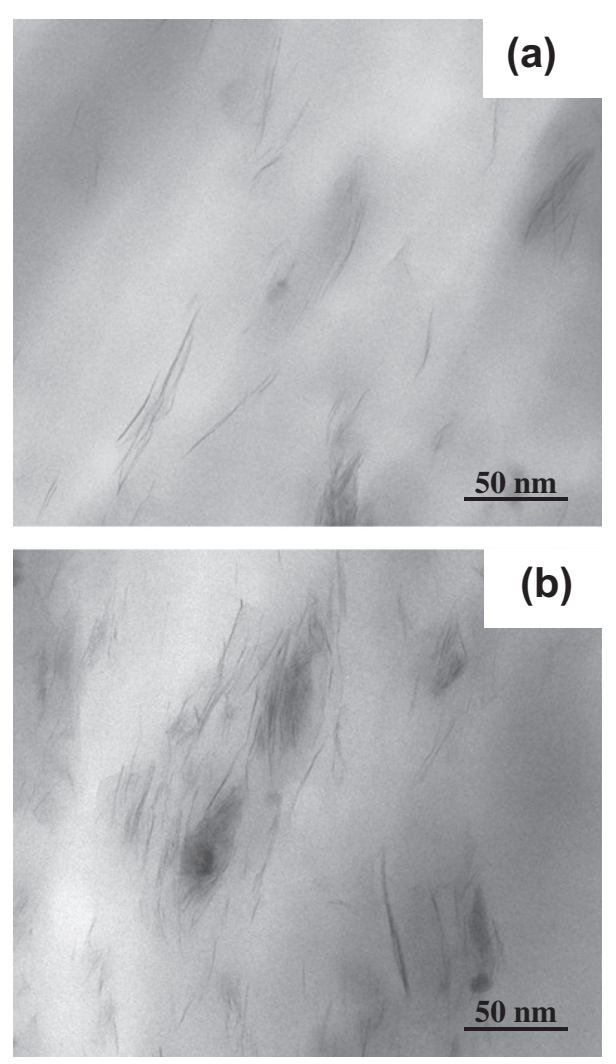

Fig. 1. TEM micrographs for: (a) Spent PA-12/5 wt.\%; (b) spent PA-12/7 wt.\%.

icate layers. Nanocomposite with 7 wt.\% layered silicates show additional dark regions, an indication of lower dispersion compared to samples at lower clay content. It is well established that homogeneous dispersion of nano particles in a polymer matrix is required to improve the properties of host matrix [20,21].

In general, clay loading at higher concentrations lead to the formation of an agglomeration of clay particles [22]. However, in this work, it is seen that the size of the clay lumps increase through the series with those in the $7 \mathrm{wt} . \%$ sample being the largest and of greater aspect ratio. This is not believed to be due to agglomeration effect of increasing clay levels, but is believed to be the result of higher viscosity at higher clay loading levels which minimises the ability of the clay to disperse evenly during processing as the clay loading is increased. Hence the 1-3 wt.\% clay filled samples show better dispersion than those at 5-7 wt.\% clay loading where the clay lumps have remained more intact (Fig. 2). This could be related to the dry grinding process used for the mixing of clays and the use of a single screw injection moulding, giving lower shear rate than that in twin screw injection moulding. The SEM micrographs for different samples as shown in Fig. 2, the clay particles appear to be larger and more visible for higher levels of clay loadings (5 and 7 wt.\%) than the lower levels, confirm the TEM results.

\subsection{Mechanical properties}

\subsubsection{Tensile strength, modulus and elongation at break}

Average values for the tensile results of five specimens tested in the tensile testing for spent PA-12 and spent PA-12/nanocomposites are presented in Table 1 . The tensile strengths for PA-12/nanocomposite specimens correspondingly increase with increasing nano clay content (up to $5 \mathrm{wt} . \%$ ). PA-12/5 wt.\% clay reinforced specimen displayed the highest strength value, an increase of $30 \%$ compared with the un-reinforced spent PA-12 sample. This in- 

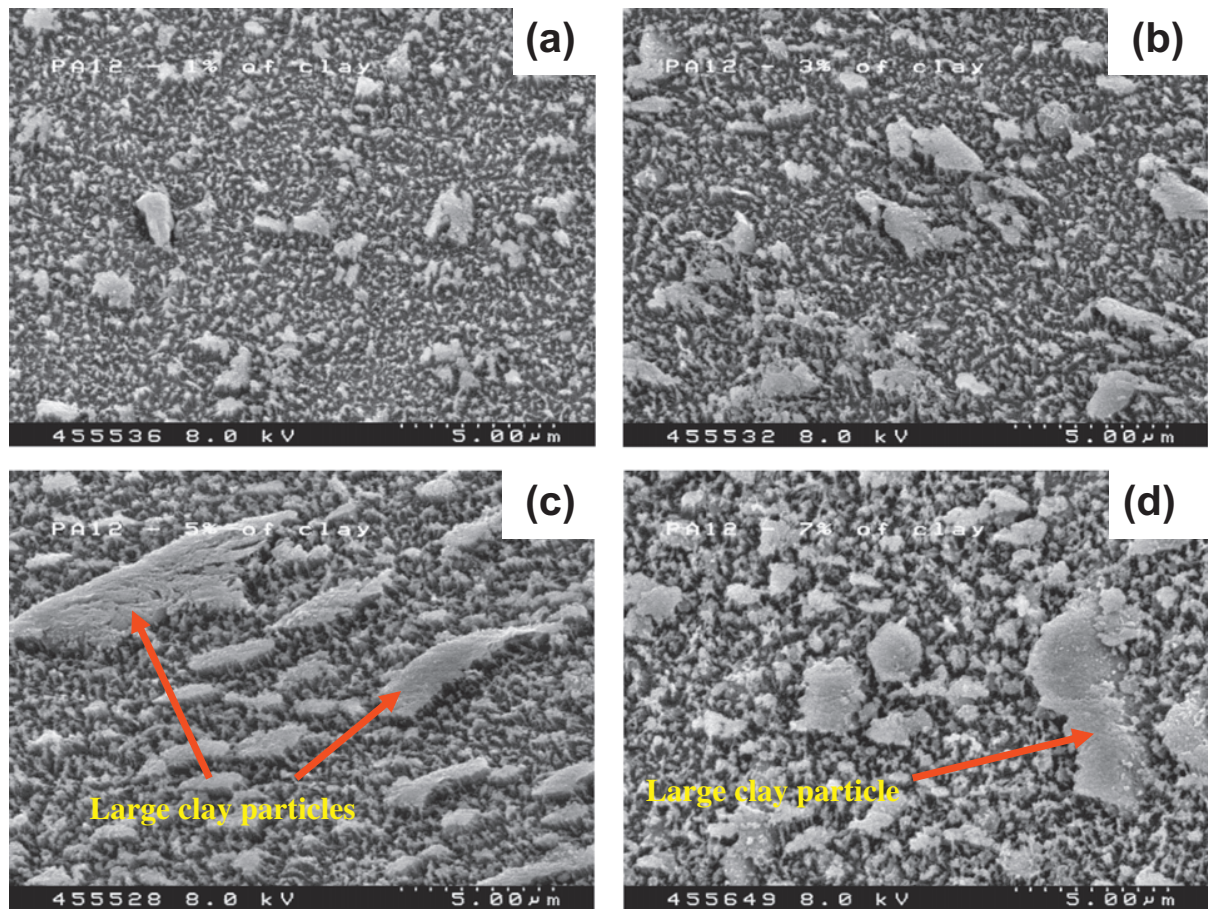

Fig. 2. SEM micrographs for: (a) Spent PA-12/1 wt.\%; (b) spent PA-12/3 wt.\%; (c) spent PA-12/5 wt.\% and (d) spent PA-12/7 wt.\%.

Table 1

Tensile properties results for spent PA-12 and its nanocomposites.

\begin{tabular}{|c|c|c|c|}
\hline Samples & Tensile strength (MPa) (SD) & Tensile modulus (GPa) (SD) & Elongation at break (\%) (SD) \\
\hline Virgin PA-12 & $55.5( \pm 6.75)$ & $0.655( \pm 0.041)$ & $462( \pm 8.48)$ \\
\hline Spent PA-12 & $40.45( \pm 3.63)$ & $0.656( \pm 0.036)$ & $324( \pm 6.94)$ \\
\hline PA-12/1 wt.\% & $44.64( \pm 4.12)$ & $0.712( \pm 0.026)$ & $353( \pm 7.94)$ \\
\hline PA-12/3 wt.\% & $48.64( \pm 1.51)$ & $0.758( \pm 0.031)$ & $439( \pm 5.40)$ \\
\hline PA- $12 / 5$ wt. $\%$ & $52.46( \pm 3.51)$ & $0.732( \pm 0.025)$ & $413( \pm 4.88)$ \\
\hline PA-12/7 wt.\% & $46.12( \pm 1.58)$ & $0.730( \pm 0.016)$ & $428( \pm 4.56)$ \\
\hline
\end{tabular}

crease can be explained as the formation of intercalated or partially exfoliated nanocomposite structures as a result of the aspect ratio of dispersed nanoparticles. This indicates that intercalated and partially exfoliated structures are the main contributors for tensile strength improvement. Another reason for the enhancement in tensile strength can be explained by the enhanced adhesion of interfacial properties between spent PA-12 and layered silicates. PA-12 is a polar polymer and contains polar groups such as $-\mathrm{NH}$, $-\mathrm{CONH}-,-\mathrm{NH}_{2}$ and $-\mathrm{COOH}$. These polar groups have favourable interactions with the polar silicate surface showing a higher compatibility between filler and matrix, hence higher reinforcement effect.

The results show that here is a reduction of tensile strength at 7 wt.\% clay sample. The decrease of tensile strength at higher clay concentration suggests that tensile strength is sensitive to structures and interaction between matrix and the reinforcement. As evidenced from TEM images, inhomogeneous dispersion of nano particles was observed at $7 \mathrm{wt} \%$ clay samples, hence decreases the mixing capability of clay into spent PA-12 matrix. Investigations carried out by Zhao et al. [19] on the mechanical properties of polyamide 12 /montmorillonite nanocomposites have also found that the mechanical properties of PA 12/MMT nanocomposites decreased after 5 wt.\% of MMT reinforcement. This behaviour according to them is attributed to the aggregation of the clay particles at higher loading concentration [23,24]. It is reasonable to say from the tensile test results that the optimum clay concentration is
$5 \mathrm{wt} . \%$ for the improvement of tensile strength for the current studied systems. With further increase in clay reinforcement, a sharp decrease in tensile strength was observed (Fig. 3a).

Contrary to tensile strength, the tensile modulus of the PA-12/ nanocomposites differs significantly. As presented in Table 1, the tensile modulus of spent PA-12/nanocomposites is shown to be markedly improved when layered silicates are used as reinforcement. Young's modulus, plotted against clay concentration in Fig 3b shows an increase as the clay content increases, more pronounced them for $3 \mathrm{wt} . \%$ clay filled samples. The increase in modulus compared to unreinforced PA-12 is an indication of modulus depending more on clay wt.\% than intercalated/exfoliated structures.

The effect of layered silicates reinforcement on the elongation behaviour of polymer nanocomposites has not been widely analysed. The elongation at break is generally reduced with the addition of fillers such as MMT on thermoplastics [1,2]. Interestingly, the elongation at break (an indicator of ductility) for the spent PA-12 and its nanocomposites in this work has increased significantly. With increasing the nanoclay (at $3 \mathrm{wt} . \%$ ), the elongation at break has increased by $35 \%$ compared with unreinforced spent PA-12 matrix. With a further increase of clay up to $7 \mathrm{wt} . \%$, the elongation at break continues to increase. This improvement may be attributed to the conformational effect at the clay-matrix interface. This result is in close agreement with the results presented by Mishra et al. [25]. Their work on organo-montomorillonite 
(a)

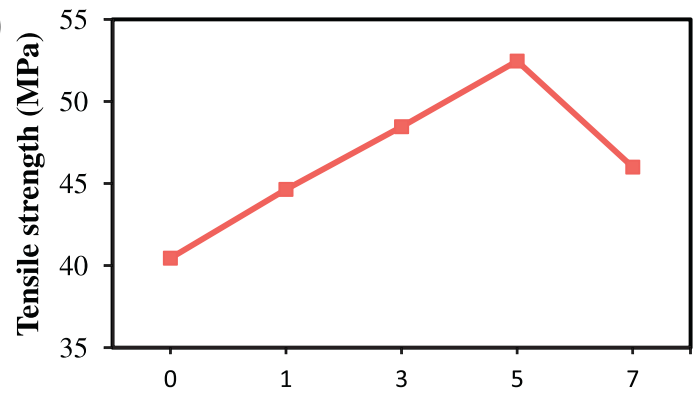

Layered silicates concentration (wt.\%)

(b)

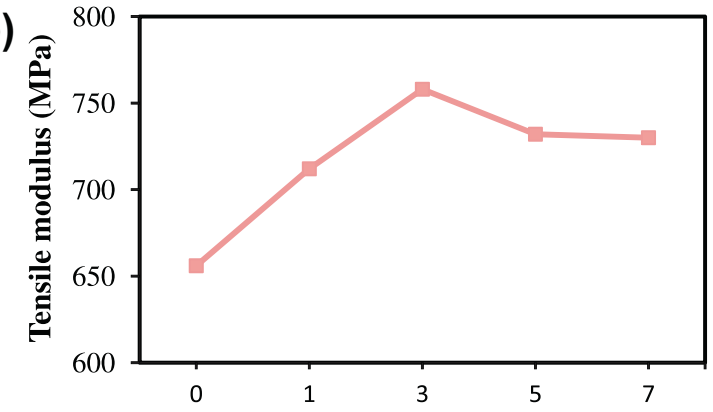

Layered silicates concentration (wt.\%)

(c)

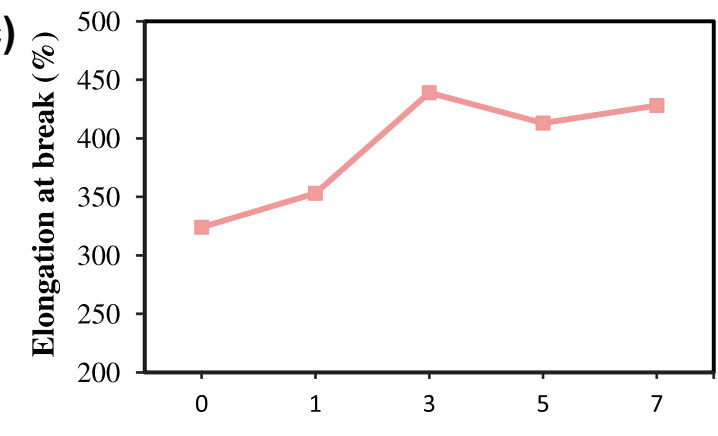

Layered silicates concentration (wt.\%)

Fig. 3. Tensile properties of spent PA-12 and its nanocomposites (a) Tensile strength; (b) tensile modulus and (c) elongation at break.

(OMMT) Polyamide nanocomposites indicates that the elongation at break increases with the increase of nanoclay content.

The main reason for adding layered silicates to spent PA-12 matrix in this work was to improve the strength and modulus. The corresponding increase in both strength and modulus evidence of fully dispersed clay which leads to the formation of intercalated/ exfoliated structures. The difference in improvements in the tensile strength, modulus and elongation at break between the various PA-12/nanocomposites is due to differences in clay dispersion. It is suggested that the initial increase in strength, modulus and elongation at break (Fig. 3b and c) would be expected with increased loading levels of clay. The decrease in properties as the clay reinforcement gets higher is believed to be linked to clay interparticle distances taking effect, in that failure cracks have a shorter distance to travel before encountering other particles, with the cracks finding it easier to travel through particle/matrix interfaces or particle cleaving, than through the neat spent PA-12 matrix itself. A further investigation is needed to confirm the above assumptions.

\subsubsection{Flexural strength and modulus}

The effects of layered silicates reinforcement on flexural properties of spent PA-12/nanocomposites are summarised in Table 2.
Table 2

Flexural properties results for spent PA-12 and its nanocomposites.

\begin{tabular}{lll}
\hline Samples & Flexural strength $(\mathrm{MPa})(\mathrm{SD})$ & Flexural modulus $(\mathrm{GPa})(\mathrm{SD})$ \\
\hline Virgin PA-12 & $91.81( \pm 2.86)$ & $2.973( \pm 0.068)$ \\
Spent PA-12 & $73.85( \pm 1.81)$ & $2.229( \pm 0.094)$ \\
PA-12/1 wt.\% & $81.58( \pm 2.12)$ & $2.443( \pm 0.091)$ \\
PA-12/3 wt.\% & $92.98( \pm 2.49)$ & $3.022( \pm 0.121)$ \\
PA-12/5 wt.\% & $90.53( \pm 4.18)$ & $2.853( \pm 0.202)$ \\
PA-12/7 wt.\% & $85.85( \pm 1.48)$ & $2.836( \pm 0.072)$ \\
\hline
\end{tabular}

(a)
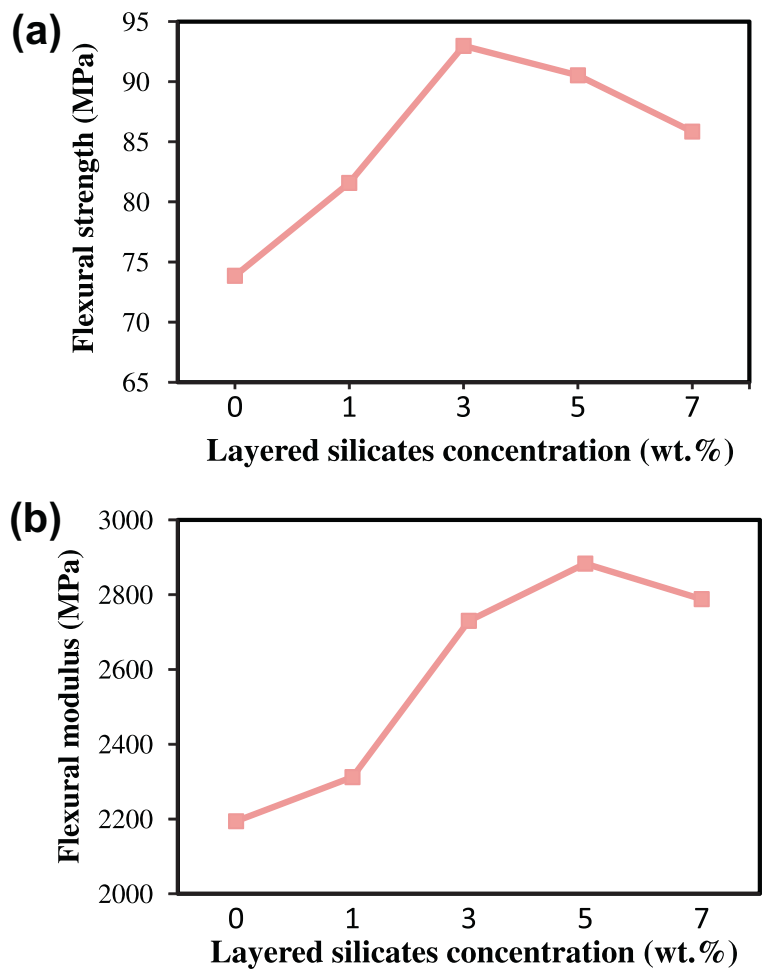

Fig. 4. Flexural properties of spent PA-12 and its nanocomposites: (a) Flexural strength and (b) flexural modulus.

The flexural strength and modulus increased with increase in LS content. The flexural strength reaches a maximum at $3 \mathrm{wt} . \%$ LS content and starts decreasing at 5 and $7 \mathrm{wt} . \%$ clay loading but is still higher than for the neat PA-12 (Fig. 4). For flexural modulus however, it approaches the highest level at $5 \mathrm{wt}$.\% clay loading and slightly drops at $7 \mathrm{wt} . \%$. These results presented here are consistent with Liu et al. [26] who found that the flexural strength decreases after (3wt.\%) of MMT loading. They indicated that the decrease in mechanical properties at higher clay concentrations could be the result of an aggregation of MMTs in composites. As explained for tensile properties, a similar trend can be observed for flexural properties. Based on the flexural results, it can be argued that flexural strength is sensitive to the degree of clay intercalation/exfoliation whereas flexural modulus is more sensitive towards the volume of clay concentrations.

\subsubsection{Comparison of results between virgin and spent PA-12/ nanocomposites}

A comparison of tensile test results between virgin PA-12, spent PA-12 and PA-12 nanocomposites are presented in Table 1 . It is worth noting that the spent sample has retained $70 \%$ of its tensile strength properties, loosened 30\% compared to virgin. Interestingly, when 5 wt.\% of layered silicate is used to reinforce spent 
material, there is an increase of approximately 30\% in tensile strength; hence the initial loss of $30 \%$ tensile strength is offset by incorporation of nanoclay. Furthermore, the environmental benefits of using spent material are enormous and difficult to quantify. If the mix ratio of $55 \mathrm{wt} . \%$ spent PA-12 to virgin PA-12 can lead to $70 \%$ of tensile properties being retained, this can be considered an acceptable property balance.

Similarly, the flexural results presented in Table 2 exhibit 80\% flexural strength retention by spent material compare to virgin. The incorporation of $3 \mathrm{wt} . \%$ nanoclay reinforcement in spent material has achieved a $20 \%$ increase in the flexural strength. This is another good example of acceptable property retention and improvement.

\section{Conclusions}

In this work, spent PA-12 and various concentrations of layered silicate reinforced spent PA-12/nanocomposites were successfully prepared using a single screw injection moulding method and their morphological and mechanical properties investigated. The morphology, as characterised by XRD, SEM and TEM, reveals good intercalation and exfoliation of clay particles into spent PA-12 matrix. As a result, the PA-12/nanocomposite samples show an improvement in their mechanical properties compared to those of the un-reinforced spent PA-12 samples. Tensile and flexural properties for PA-12/nanocomposites specimens correspondingly increase with increasing nanoclay content. It can be concluded that the reinforcement effect of layered silicate in spent PA-12/nanocomposites increases with the increase of clay content up to $5 \mathrm{wt}$.\% for strength and up to $7 \mathrm{wt} . \%$ for modulus. Above this the ability of clay to disperse within spent PA-12 is lowered as a consequence of parameters, such as increased viscosity which minimises the ability of the clay particles to break down during processing as the clay loading is increased. In the view of these improved mechanical properties, spent PA-12 (mix ratio of 55 wt.\% spent and 45 wt.\% virgin) are promising candidates using PA-12/nanocomposites for engineering applications.

\section{Acknowledgement}

The authors wish to thank Centre for Rapid Design and Manufacturing (CRDM) Ltd., for providing the spent polyamide-12.

\section{References}

[1] Alexandre M, Dubois P. Polymer-layered silicate nanocomposites: preparation, properties and uses of a new class of materials. Mater Sci Eng: R - Reports 2000;28:1-63.
[2] Ray S, Okamoto M. Polymer/layered silicate nanocomposites: a review from preparation to processing. Prog Polym Sci 2003;28:1539-641.

[3] Dai Y, Mai Y, Ji X. Predictions of stiffness and strength of nylon 6/MMT nanocomposites with an improved staggered model. Composites: Part B 2008;39:1062-8.

[4] Abdel-Goad M. Rheological characterization of melt compounded polypropylene/clay nanocomposites. Composites: Part B 2011, doi:10.1016/ j.compositesb.2011.03.025.

[5] Kojima Y, Usiki A, Kawasumi M, Okada A, Fukushima Y, Karauchi T, et al. Mechanical properties of nylon-6 clay hybrids. J Mater Res 1993;8:1185-9.

[6] Usuki A, Kojima Y, Kawasumi M, Okada A, Fukushima Y, Kurauchi T, et al. Synthesis of nylon 6-clay hybrid. J Mater Res 1993;8:1179-84.

[7] Zeng QH, Yu GQ Lu M, Paul DR. Clay-based polymer nanocomposites: research and commercial development. J Nanosci Nanotechnol 2005;5:1574-92.

[8] Cho JW, Paul DR. Nylon 6 nanocomposites by melt compounding. Polymer 2001:42:1083-94.

[9] Fornes TD, Paul DR. Crystallization behaviour of nylon 6 nanocomposites. Polymer 2003;44:3945-61.

[10] Shen L, Phang IY, Chen L, Liu T, Zeng K. Nanoindentation and morphological studies on nylon 66 nanocomposites. Polymer 2004;45:3341-9.

[11] Shen L, Tjiu WC, Liu T. Nanoindentation and morphological studies on injection-molded nylon-6 nanocomposites. Polymer 2005;46:11969-77.

[12] Liu T, Lim PK, Tjiu CW, Pramoda KP, Chen Z. Preparation and characterization of nylon11/organoclay nanocomposites. Polymer 2003;44:3529-35.

[13] Yu S, Zhao J, Chen G, Juay Y, Yong M. The characteristics of polyamide layeredsilicate nanocomposites. J Mater Process Technol 2007(192-193):410-4.

[14] Zhang X, Yang G, Lin J. Synthesis, rheology, and morphology of nylon-11/ layered silicate nanocomposite. J Polym Sci: Part B: Polym Phys 2006;44: 2161-72.

[15] Hu Y, Shen L, Yang H, Wang M, Liu T, Liang T, et al. Nanoindentation studies on nylon 11/clay nanocomposites. Polym Test 2006;25:492-7.

[16] McNally T, Raymond MW, Lew CY, Turner RJ, Brennan GP. Polyamide-12 layered silicate nanocomposites by melt blending. Polymer 2003:44:2761-72.

[17] Phang IY, Liu T, Mohamed A, Pramoda KP, Chen L, Shen L, et al. Morphology, thermal and mechanical properties of nylon 12/organoclay nanocomposites prepared by melt compounding. Polym Int 2005;54:456-64.

[18] Meng Z, Wang Z, Zhao XD, Bi W, Tang T. Morphology evolutions of organically modified montmorillonite/polyamide 12 nanocomposites. Polymer 2007;48: 2508-19.

[19] Zhao F, Bao X, McLauchlin AR, Gu J, Wan C, Kandasubramanian B. Effect of POSS on morphology and mechanical properties of polyamide 12/ montmorillonite nanocomposites. Appl Clay Sci 2010;47:249-56.

[20] Dhakal HN, Zhang ZY, Richardson MOW. Nanoindentation behaviour of layered silicates reinforced unsaturated polyester nanocomposites. Polym Test 2006;25:846-52.

[21] Ray SS, Malwela T. Unique morphology of dispersed clay particles in a polymer nanocomposite. Polymer 2011;52:1297-301.

[22] Jordan J, Jacob KI, Tannenbaum R, Sharaf MA, Jasiuk I. Experimental trends in polymer nanocomposites-a review. Mater Sci Eng A 2005;393:1-11.

[23] Xiong J, Liu Y, Yang X, Wang X. Thermal and mechanical properties of polyurethane/montmorillonite nanocomposites based on a novel reactive modifier. Polym Degrad Stab 2004;86:549-55.

[24] Tarapow JA, Bernal CR, Alvarez VA. Mechanical properties of polypropylene/ clay nanocomposites: effect of clay content, polymer/clay compatibility, and processing conditions. J Appl Polym Sci 2009;111:768-78.

[25] Mishra S, Sonawane SS, Shimpi NG. Influence of organo-montomorillonite on mechanical and rheological properties of polyamide nanocomposites. Appl Clay Sci 2009;46:222-5

[26] Liu S, Hwang S, Yeh J, Hung C. Mechanical properties of polyamide-6/ montmorillonite nanocomposites - prepared by the twin-screw extruder mixed technique. Int Commun Heat Mass Transfer 2011;38:37-43. 